\title{
Problematizando o papel de intérpretes surdos(as) em escolas regulares
}

\author{
Deaf interpreters' roles and its problematizing in regular schools
}

\section{Problematización del papel de intérpretes sordos(as) en escuelas regulares}

\section{Lucas Romário'}

Universidade Federal do Cariri, Curso de Licenciatura em Letras-Libras, Professor Adjunto. https://orcid.org/0000-0002-9952-9515

\section{Ana Dorziat ${ }^{2}$}

Universidade Federal de Campina Grande, Programa de Pós-Graduação em Educação, Professora Uisitante.

https://orcid.org/0000-0002-1973-3613

Resumo: Resultado de uma pesquisa de tese de doutorado em Educação, este artigo problematiza a forma de incorporação do trabalho de pessoas surdas na função de intérpretes em escolas regulares de João Pessoa - PB. A pesquisa qualitativa ancorou-se no escopo teórico dos Estudos Surdos em articulação com o campo dos Estudos Culturais da Educação e foi desenvolvida com profissionais surdos(as) de sete escolas públicas ${ }^{3}$. As análises das entrevistas apontaram que as pessoas surdas não possuíam formação na área de tradução-interpretação; seus salários eram inadequados, uma vez que, mesmo alguns(algumas) tendo formação em nível superior, recebiam salário de nível médio; e, principalmente, as condições de uso linguístico desse trabalho eram questionáveis, considerando que a tradução/interpretação deveria ser realizada da língua oral para a língua de sinais e vice-versa (tradução intermodal).

Palavras-chave: Intérpretes surdos(as). Escolas regulares. Língua de sinais.

Abstract: As result of a doctoral dissertation research about Education, this article problematization focuses on the way of incorporation of deaf people's work as interpreters in Regular Schools of João Pessoa, Paraiba, Brazil. The qualitative research was anchored on theorical Deaf Studies considering the Cultural Education Studies area, also developed with deaf professionals from seven public schools. The intreview analysis showed that deaf people did not have official formation in the area of translation/ interpretation - their salaries were inappropriate even if some of them had a higher education, so they

Doutor e Mestre em Educação pela Universidade Federal da Paraiba.

Pós-doutora pela Universidade de Lisboa, Portugal; Doutora em Educação pela Universidade Federal de São Carlos.

A pesquisa foi submetida a um Comitê de Ética em Pesquisa (CEP) de uma Instituição de Ensino Superior (IES). 
received high school salaries, and the central point was that the conditions of linguistic use of their work were questionable, considering that the translation /interpretation should be performed from oral to sign language and vice versa (intermodal translation).

Keywords: Deaf interpreters. Regular Schools. Sign linguage.

Resumen: Resultado de una investigación de tesis de Doctorado en Educación, este artículo problematiza la manera de incorporación del trabajo de personas sordas en la función de intérpretes en escuelas regulares de João Pessoa, Paraíba, Brasil. La investigación cualitativa se ancoró en el alcance teórico de los Estudios Sordos articulado con el campo de los Estudios Culturales de Educación y fue desarrollada con profesionales sordos(as) de siete escuelas públicas. Los análisis de las entrevistas apuntaron que las personas sordas no poseían formación en el área de traducción-interpretación; sus salarios eran inadecuados, una vez que, aunque algunos/algunas tengan formación en nivel superior, recibian salario de nivel medio; $y$, principalmente, las condiciones de uso lingüístico de ese trabajo eran cuestionables, considerando que la traducción-interpretación debería ser realizada de la lengua oral para la lengua de señales y viceversa (traducción intermodal).

Palabras clave: Intérpretes sordos(as). Escuelas regulares. Lengua de señas.

Recebido em 13 de agosto de 2020 Aceito em 24 de fevereiro de 2021

\section{INTRODUÇÃO}

Diversas pesquisas têm demonstrado o despreparo escolar em relação ao trabalho com alunos(as) surdos(as), considerando a inabilidade em língua de sinais e falta de interação com os(as) alunos(as) surdos(as) (DORZIAT, 2015), a indiferença e a desvalorização da Língua Brasileira de Sinais (Libras) por meio do desinteresse de docentes em aprendê-la (DORZIAT; ARAÚJO; SOARES, 2012; LIMA, 2012), etc. Esse contexto das escolas regulares é configurado, em grande parte, pela ausência de intérpretes educacionais, como aponta o estudo de Lopes e Menezes (2010), que mostra a importância da presença desses profissionais como única via de acesso das pessoas surdas ao conhecimento. Nessa mesma direção, Dorziat Araújo e Soares (2017, p. 54) afirmam que "o intérprete de Libras é peça fundamental para amenizar as dificuldades comunicativas entre os alunos surdos e os demais componentes da escola regular." Sem eles(as), a permanência de estudantes surdos(as) nas escolas regulares é inócua.

Todavia, essa presença precisa ser pensada de maneira integral, para além da presença física. Segundo Martins e Nascimento (2016, p. 110), "[...] no campo da educação, a atuação do intérprete, bem como sua função, é algo que ainda não está clara e traz controvérsias." 0 
papel de intérpretes educacionais é apenas traduzir os conhecimentos e informações de uma língua para outra - Língua Portuguesa para Libras e vice-versa? Souza (2007) considera que não. Para ela, o(a) intérprete educacional é, antes de qualquer coisa, um(a) educador(a), pois participa da formação de estudantes no espaço escolar. Ela acredita que, nesse espaço, a interpretação apenas como uma questão técnica é algo quase impossível.

Essa ideia parte da visão de que os intérpretes se investem naturalmente do papel de educadores(as) porque a interpretação entre línguas, em um ambiente educacional, de formação humana, toma como instrumento as línguas enquanto artefato cultural (STROBEL, 2013) e, como tal, está inequivocamente imbricada na construção de conhecimentos.

A atribuição da mera função técnica (tradutor de línguas) do(a) intérprete na mediação da relação docente-discente simplifica, portanto, seu papel, limitando sua formação e suas funções pedagógicas em etapas importantes do processo educacional, como o planejamento pedagógico, a prática pedagógica e a avaliação dos conhecimentos.

Quanto à prática pedagógica, surgem contradições durante todo o processo educacional. Pelo fato de a prática sob os moldes de aplicação da técnica não ser suficiente, os(as) intérpretes, mesmo sem uma formação adequada e suficiente, terminam tendo que desenvolver a tarefa educativa de acompanhamento, identificação de dificuldades e, quase sempre, intervenção, já que possuem maiores possibilidades de conhecerem a diferença surda e os processos históricos de exclusão educacional das pessoas surdas. Esse perfil, adquirido no caminho trilhado durante a aprendizagem da Libras, que proporciona uma proximidade com a cultura surda, e a prática educacional construída pela escola nesse cenário, confere aos(às) intérpretes educacionais a condição de educadores(as) por excelência.

Mesmo desconsiderando essas reflexões como pano de fundo para uma atuação adequada de intérpretes de pessoas surdas no âmbito educacional, e fixando a atenção apenas na recomendação da política pública de inclusão, que ressalta a função técnica desses(as) profissionais - sanar as dificuldades comunicativas entre pessoas ouvintes da comunidade escolar e alunos(as) surdos(as) -, há um critério básico do qual não se pode eximir: os(as) profissionais intérpretes devem ser pessoas ouvintes proficientes em língua de sinais, condição que lhes permite intermediar a comunicação da língua portuguesa falada para a Libras e vice-versa.

Este critério básico para o exercício profissional de intérpretes foi razão para estranhamento de um fato que se deu na rede pública de ensino de João Pessoa - PB: foram contratados(as) intérpretes surdos(as) para atuarem em salas de aula que possuíam 
alunos(as) surdos(as) ${ }^{4}$, para interpretar da lingua oral (língua portuguesa) para a língua gestual-visual (Libras) os conteúdos que os(as) professores(as) ouvintes ensinavam.

Esse aspecto instigou nossa curiosidade investigativa, que se concretizou numa pesquisa de tese que teve por objetivo identificar e problematizar as formas de incorporação do trabalho pedagógico surdo na escola regular, visto que além de intérpretes em salas de aula regular, também os(as) profissionais surdos(as) atuavam como professores(as) do Atendimento Educacional Especializado (AEE). Este artigo é produto, portanto, de um recorte da tese em que apresentamos a problematização realizada em torno da incorporação do trabalho de pessoas surdas como intérpretes em escolas regulares.

\section{CAMINHOS METODOLÓGICOS}

Este estudo foi desenvolvido em sete escolas públicas de bairros periféricos de João Pessoa - PB, as quais possuíam os(as) profissionais surdos(as) que atuavam no AEE e/ou na sala de aula regular. Neste artigo serão apresentados os dados narrativos de dez profissionais surdos(as) que atuavam como intérpretes:

a) Sabrina: ${ }^{5}$ graduada em Licenciatura em Letras-Libras, especialista em Libras, possuía dois anos de profissão e atuava na escola pesquisada havia dois anos;

b) Silas: graduado em Licenciatura em Pedagogia e em Licenciatura em LetrasLibras, especialista em Educação Inclusiva, possuía 15 anos de profissão e atuava na escola pesquisada havia dois anos;

c) Sofia: graduanda em Licenciatura em Letras-Libras, possuía um ano de profissão e atuava pelo mesmo período na escola pesquisada;

d) Sandra: graduanda em Licenciatura em Letras-Libras, possuía cinco anos de profissão e atuava na escola pesquisada havia um ano;

e) Samuel: graduado em Licenciatura em Letras-Libras, possuía oito anos de profissão e atuava na escola pesquisada havia um ano; 
f) Samir: graduando em Licenciatura em Pedagogia, sua primeira experiência foi na escola pesquisada e atuava havia apenas três meses;

g) Silvio: graduando em Licenciatura em Pedagogia, possuía um ano de profissão e atuava na escola pesquisada havia cinco meses;

h) Samanta: graduada em Licenciatura em Letras-Libras, graduanda em Licenciatura em Pedagogia Bilíngue, possuía sete anos de profissão e atuava na escola pesquisada havia três meses;

i) Silvana: graduada em Licenciatura em Letras-Libras, especialista em Libras, possuía 26 anos de profissão e atuava na escola pesquisada havia nove meses;

j) Suelen: graduanda em Licenciatura em Letras-Libras, sua primeira experiência era na escola pesquisada e atuava havia apenas quatro meses.

Para a obtenção das narrativas dos sujeitos, foi escolhida a entrevista que, de acordo com Silveira (2007), pode ser considerada uma arena de significados. Cunha (1997, p. 189) afirma que, quando se trata de pesquisa com professor(a), "através da narrativa elela] vai descobrindo os significados que tem atribuído aos fatos que viveu e, assim, vai reconstruindo a compreensão que tem de si mesmo." Nesse sentido, compreendemos que as narrativas são relatos de um determinado sujeito sobre fatos, acontecimentos históricos, objetos, sobre si ou sobre aquilo em que está envolvido.

A análise dos dados foi norteada pela pesquisa qualitativa (DENZIN; LINCOLN, 2006), articulando os dados empíricos com os referenciais teóricos dos Estudos Surdos em interface com os Estudos Culturais da Educação.

\section{AS FORMAS DE INCORPORAÇÃO DO TRABALHO DE INTÉRPRETES SURDOS(AS) NAS SALAS DE AULA REGULARES}

Diferentemente do que tem sido comum nas escolas regulares que possuem alunos(as) surdos(as) de todo o Brasil, em que há forte presença de intérpretes ouvintes de Libras, nas escolas pessoenses foram inseridos(as) intérpretes surdos(as) para exercerem a função de tradução e interpretação da língua oral para a língua de sinais.

Essa situação estava sendo incorporada pela escola regular, segundo Silvana, da seguinte forma: 
Então, aqui, o contrato está errado porque diz que sou intérprete de Libras. A minha opinião é que está errado porque a pessoa surda é professora de Libras, então, o contrato está errado e eu já falei lá que isso precisa mudar. As pessoas precisam entender que é professora de Libras. [...] Não concordo! Jamais! Eu discordo! 0 certo é professora de Libras, porque eu me formei como professora de Libras, eu estudei, fiz faculdade. Eu sou surda, então, sou professora de Libras. Quando o intérprete também é formado em Letras-Libras, tudo bem, ele também é professor [...] (Silvana, 26/11/2018) (informação verbal).

Silvana é a surda mais experiente do grupo de educadores(as) surdos(as). Possuía 26 anos de carreira. Na posição de pessoa com bastante experiência, ela expressou sua indignação em relação ao contrato ao qual ela e seus(suas) colegas estavam sujeitos(as), recorrendo, primeiramente, ao aspecto formativo.

Para entender essa justificativa, é importante retomar características do curso de Licenciatura em Letras-Libras, no qual a educadora era formada. Tal curso visa a formação de docentes, com ações voltadas para o ensino, diferentemente do curso de Bacharelado em Letras-Libras, que objetiva a formação para a tradução e interpretação. No Brasil, atualmente, existem cursos que visam a formação de profissionais da área de tradução e interpretação em Libras-Português, sendo que nenhum possui ações voltadas especificamente para a formação de tradutores(as), intérpretes e guia-intérpretes surdos(as), conforme aponta Ferreira (2019), mesmo já tendo formado algum(as). Nesse sentido, a crítica é legítima, visto que, embora haja, atualmente, uma abertura do campo de tradução e interpretação para os sujeitos surdos, é importante considerar a formação e o espaço onde esse trabalho é desenvolvido.

A importância da formação docente, ratificada por Silvana, está de acordo com o que diz Carvalho (2016). Este autor surdo sustenta que ser surdo não deve ser o único critério para a atuação docente, apesar de considerar que a diferença cultural surda tem um peso substancial no exercício do ensino de Libras. A partir desse entendimento, ele defende uma formação docente adequada para os(as) surdos(as). 0 mesmo deve acontecer com relação à atuação como intérprete. A função requer da pessoa surda, além de fluência linguística e identidade cultural, formação adequada, como defende Campello (2014), por entender que a formação para atuar como Tradutor(a)-Intérprete de Língua de Sinais (TILS) deva ser na área de tradução.

Ferreira (2019, p. 39) aponta que "há muitos elementos culturais imbricados na tradução de/entre/para língua de sinais e que, portanto, os intérpretes surdos são fundamentais por possuírem, em muitos casos, um senso mais apurado de suas culturas." Contudo, em nenhum momento o autor surdo descarta a importância dos processos 
formativos para esses(as) profissionais; pelo contrário, sinaliza que é importante que os currículos dos cursos da área de tradução e interpretação de Libras incluam a formação de surdos(as) como TILS.

Isso quer dizer que a formação em tradução-interpretação em línguas de sinais deve considerar competências próprias da área, haja vista que o fato de ser uma pessoa surda bilíngue não a capacita integralmente para essa função. Conforme Rodrigues (2018), é necessário compreender que as habilidades e os conhecimentos linguísticos são apenas um dos componentes da Competência Tradutória, que pode ser definida como:

0 conjunto de conhecimentos, habilidades e atitudes que um(a) tradutor(a)intérprete deve possuir para desempenhar adequadamente sua atividade profissional. É um tipo de conhecimento especializado que combina conhecimento declarativo (saber o quê) e conhecimento procedimental (saber como), sendo predominantemente procedimental. (MUNDAY, 2009, p. 234, tradução nossa).

A Competência Tradutória, assim, só pode ser aprendida em cursos de formação específica. Os Cursos de Licenciatura em Letras-Libras, que têm como foco a docência, portanto, não abrangem as diversas competências que os cursos de formação em tradução e interpretação promovem. Esse conjunto de conhecimentos, habilidades e atitudes é composto por:

\footnotetext{
[...] vários componentes ou subcompetências inter-relacionadas, das quais as mais importantes são a competência comunicativa e textual em duas lou mais) linguas; a competência extralinguística (conhecimento enciclopédico, cultural e de conteúdo, bem como o conhecimento sobre tradução); competência instrumental (a capacidade de utilizar fontes documentais relevantes e ferramentas tecnológicas aplicadas à tradução); competência profissional (conhecimento sobre o mercado de trabalho); a competência estratégica (relacionada à resolução de problemas e tomada de decisões). (MUNDAY, 2009, p. 234-235, tradução nossa).
}

A partir do exposto, é fundamental que as formações em tradução e interpretação, que visem a atuação em diversos contextos, caminhem em duas direções: o da competência tradutória e o de conhecimentos que englobem a cultura surda.

Temos visto pessoas surdas atuando como tradutoras-intérpretes na televisão, no cinema, nas redes sociais, nos debates políticos, no âmbito jurídico, em eventos acadêmicos internacionais, nos cursos de formação superior a distância, entre outros espaços, como resultado de seus próprios esforços e competência. Entretanto, temos que considerar que esta pesquisa buscou um ambiente específico - o escolar -, cujas condições para a atuação 
dos sujeitos surdos como tradutores-intérpretes eram adversas, porque eles: não tinham a devida formação na área de tradução e interpretação; recebiam salários de nível médio, mesmo algumas tendo formação em nível superior; e, sobretudo, deviam realizar a tradução e interpretação intermodal: da língua vocal-auditiva para a gestual-visual.

Jakobson (2007) distingue três tipos de tradução: intralingual, interlingual e intersemiótica. A tradução intralingual equivale a interpretar signos verbais por meio de outros signos da mesma língua; a tradução interlingual equivale a interpretar signos verbais por meio de alguma outra língua; e a tradução intersemiótica equivale à interpretação dos signos verbais por meio de sistemas de signos não-verbais. Rodrigues (2018, p. 118) diferencia também os conceitos de tradução de interpretação:

A tradução envolve a manipulação de textos escritos, devidamente registrados, por meio de um processo que se realiza sem o contato direto com o público, permitindo que o tradutor siga seu próprio ritmo, use apoio externo, faça a revisão antes do conhecimento do público e, portanto, possa apresentar um produto registrado, burilado e duradouro. Já a interpretação abrange $o$ trabalho com textos orais, em seu fluxo de produção, por meio de um processo imediato que se realiza em contato com o público, não permitindo que o intérprete interrompa o processo para recorrer a apoios externos, já que deve seguir o ritmo do autor do texto. 0 produto do trabalho é efêmero, já que não é automaticamente registrado, e não pode ser revisado antes do conhecimento do público.

Contudo, Segala (2010) ressalta que na tradução de Língua Portuguesa para Libras, a tradução interlingual não condiz com essa especificidade linguística, pois trata-se de línguas de diferentes modalidades, portanto, "tradução intermodal". Nesta direção, Rodrigues (2018, p. 118) explica que:

[...] considerando a questão da modalidade de língua aplicada à tradução e à interpretação, temos como delinear dois tipos de processos: os intramodais e os intermodais. Os processos intramodais são aqueles que ocorrem entre línguas de uma mesma modalidade, seja entre duas linguas orais ou entre duas linguas de sinais (Português-Inglês, Francês-Espanhol, ASL [American Sign Language/Língua de Sinais Americana]-Libras, BSL [British Sign Language/Lingua de Sinais Britânica]-LSF [Langue des Signes Française/Lingua de Sinais Francesal etc.). Já os processos intermodais são aqueles que se realizam entre uma língua oral e outra de sinais (lnglêsASL, Francês-Libras, LSF-Inglês, Português-Libras etc.) [...]

Sendo assim, no caso específico desta pesquisa, poderíamos caracterizar como um trabalho de interpretação intermodal, desde que os(as) intérpretes não fossem surdos(as). 
A seguir, as narrativas das demais profissionais surdas sobre as situações que vivenciavam como intérpretes expuseram, também, questões complexas que envolvem a sua condição linguístico-cultural e, por conseguinte, o seu trabalho pedagógico surdo:

\begin{abstract}
Eu gosto de ser professora, mas intérprete... 0 que eu vou fazer? 0 professor está lá passando, mas não me explica, e eu vou fazer o quê? Intérprete? Não combina, não! Eu sou formada em Letras-Libras, eu tenho um estágio também na área, então, não combina com intérprete. 0 meu foco é ser professora em Libras, esse é o meu foco, então, intérprete não combina. Eu sou ouvinte? Não, eu sou surda. E ai? Aí a professora começa a explicar, começa a fazer, então, ela vai me dar para eu ver, como eu não escuto, então, eu pego ali e faço a adaptação, mas intérprete? Eu, surda? Impossível. Eu faço a adaptação na escrita, eu vejo o conteúdo e faço uma interpretação, mas questão de audição, não. Na minha opinião, eu sou professora, a minha fluência é em Libras, e eu gosto, mas para interpretar, isso é muito diferentel (Sabrina, 26/07/2018).
\end{abstract}

Instrutora? No começo eu sempre confundia isso, o intérprete e o instrutor e o professor de Libras, aí tem o grupo dos intérpretes e eu fiquei confusa. Pensaram que eu era intérprete, ai eu fui explicar para outra pessoa... Mas, no contrato está como intérprete... Mas, na escola sou instrutora. Eu me sinto instrutora! (Suelen, 24/10/2018).

Eu comecei a minha experiência agora, mas eu acho um pouco estranho essa questão de intérprete surdo, eu me sinto professora. Eu acho que a responsabilidade da escola também é ter intérpretes e aqui eu sou a única intérprete, eu acho que essa é uma responsabilidade da escola também. Então, é estranho. Eu sou surda, como é que eu vou lá, o ouvinte fica lá na sala [...] é muito confuso. Essa questão é complicada, a gente está lá fazendo as adaptações, é confuso. (Samanta, 09/11/2018).

Eu não sei (risos). As pessoas já me falaram de intérprete surdo, lá na UPPB [Universidade Federal da Paraiba], falou de intérprete surdo e as pessoas: "Tem? Intérprete surdo, como?". As pessoas ficam confusas. Antes tinha o monitor, instrutor e agora o intérprete surdo, é complicado. Eu não sei opinar, é complicado. 0 intérprete surdo [...] parece que é ouvinte, a surda que é a professora, parece que trocou, eu não sei. Exemplo: eu, agora, eu sou surda, mas trabalhando como intérprete, como eu vou interpretar se eu sou surda? Não. Um exemplo, eu ensino [...] o professor fica, às vezes: "me interprete na sala de aula", eu respondo: "não, eu não sou intérprete". Ele fala: "você não é intérprete?", eu respondo novamente: "eu sou surda! Como eu vou interpretar?". Às vezes, o professor me chama para interpretar e isso é muito confuso, é complicado para mim que sou surda. (Sandra, 27/08/2018) (informações verbais).

Nesse caso, é inevitável não levarmos em consideração o aspecto biológico das pessoas surdas (a surdez), de forma reversa. Se historicamente ela foi usada para marcar uma visão clínica (ouvintista), aqui usamos esse aspecto como marca para a reivindicação de 
um território visual, linguístico, cultural. Tomamos para nós as palavras de Lopes (2007, p. 9, grifo da autora), quando afirma:

\begin{abstract}
Não nego a falta de audição do corpo surdo, porém desloco meu olhar para o que os próprios surdos dizem de si quando articulados e engajados na luta por seus direitos de se verem e de quererem ser vistos como sujeitos surdos, e não como sujeitos com surdez. Tal diferença, embora pareça sutil, marca substancialmente a constituição de uma comunidade específica e a constituição de estudos que foram produzindo e inventando a surdez como marcador cultural primordial.
\end{abstract}

Os Estudos Surdos (campo teórico ao qual se ancora este estudo), desse modo, não negam a surdez como uma materialidade corpórea, contudo, a ressignificam a partir da ótica antropológica, ressaltando aquilo que é produzido para além da marca física. Focalizam a cultura visual, essa experiência cultural que é construída ao longo da história das pessoas surdas, por meio de suas identidades constituídas pela visualidade, que constrói a língua de sinais.

Diante disso, questionamos os pressupostos dessa função de intérpretes surdos(as) em suas salas de aula regulares, inventada pelo sistema educacional de João Pessoa - PB, uma vez que eles contribuem para demarcar um território discursivo e simbólico, que as pessoas surdas vêm lutando historicamente para desnaturalizar: o da marca corpórea (surdez) como fator de desvalorização.

Foi esse discurso clínico de surdez que contestou as reivindicações históricas das pessoas surdas em torno de uma concepção antropológica de língua, cultura, educação, entre outras. Dessa forma, em plena época em que a língua de sinais ocupa um lugar próximo do ansiado pela comunidade surda, inclusive com o reconhecimento de sua importância, consolidada com a formação em curso de Letras-Libras, essa situação vem causando estranhamento, como salientou Samanta, ofuscando a busca pela valorização da cultura surda, especialmente por meio da sobreposição da língua oral em relação à língua de sinais, mesmo que esta estivesse também em uso no contato dos(as) educadores(as) com as crianças surdas.

Essa perspectiva biológica é trazida à baila por algum(as) dos(as) educadores(as) surdos(as), quando falam da atividade de interpretação em sala de aula. As narrativas, entretanto, pareciam não ser consensuais.

A opinião de Silvio era de que ele era colocado em uma situação muito difícil, haja vista que sua condição orgânica não o permitia desenvolver a função para a qual havia sido designado. Sua narrativa demonstra essa insatisfação de, em sendo surdo, ser exposto a esse tipo de situação. Disse ele: 
Eu tenho vontade de ficar junto com o intérprete que trabalha lá, porque eu sou surdo, sozinho lá. Por exemplo, acontecem palestras lá, tem o telão, as imagens e os ouvintes percebem tudo, a pessoa está falando lá, e eu? Desculpa, eu sou surdo, não consigo traduzir, só consigo ensinar Libras e pronto. Precisa de um intérprete para os surdos, já expliquei. Por exemplo, a AIDS [Acquired Immunodeficiency Syndrome/Síndrome da Imunodeficiência Adquirida], aconteceu lá um projeto sobre a AIDS, uma palestra explicando e eu não entendi nada, eu não consegui passar. Eu sou surdo, é difícil. Pedi desculpa, mas aí eu fiz um resumo mais ou menos do que eu sabia: que era uma doença, que é um vírus e tal. Aí eu fui resumindo e explicando, fui mostrando imagem e quando viam a imagem percebiam como as doenças aconteciam e tal. Mas falta uma explicação ampla, eu não consegui porque era só para o ouvinte e não tinha intérprete, eu quero o intérprete. É muito difícil ser um surdo sozinho lá. (Silvio, 18/09/2018) (informação verbal).

Isso mostra que embora haja um discurso de valorização da lingua de sinais, parece que a escola ainda carece de uma discussão mais profunda sobre as concepções que envolvem a condição surda e os elementos culturais que a envolvem. As iniciativas relativas às formas de comunicação de os conhecimentos serem veiculados às pessoas surdas precisam considerar também as questões curriculares que envolvem as trajetórias de vida dessas pessoas, suas possibilidades, capacidades, competências e contribuições no processo educacional. Mas os depoimentos anteriores mostram que acontece o oposto: 0 destaque é dado à diferença sensorial como falta, ausência, incapacidade. A oportunidade de fortalecer um convívio saudável com as diferenças no meio educacional é desperdiçada, deixando-se de lado o potencial pedagógico das pessoas surdas.

Uma saída para sanar esse problema seria acatar a sugestão do próprio educador surdo, para quem seria necessária a presença de um(a) intérprete ouvinte, interpretando a fala oral do(a) professor(a) para a língua de sinais (tradução interlingual - JAKOBSON, 2007; e intermodal, SEGALA, 2010), e de um(a) surdo(a), como ele, interpretando e ensinando a criança surda por meio da língua de sinais (tradução intralingual - JAKOBSON, 2007; e intramodal SEGALA, 2010). Esse processo de interpretação, envolvendo dois(duas) TILS em um trabalho em equipe, poderia se aproximar ao que os Estudos da Tradução têm chamado de feedback e ola) profissional surdo(a) que atua nesse processo de tradução tem sido chamado(a) de intérprete intramodal gestual-visual surdo(a), segundo Ferreira (2019).

Conquanto a escola regular não seja a melhor alternativa educacional, uma vez que a escola bilíngue representa um processo mais adequado às crianças surdas, porque nela a língua de sinais seria a língua de instrução e as pessoas surdas poderiam ser as principais responsáveis pela educação das crianças surdas no papel docente; o trabalho dola) intérprete intramodal gestual-visual surdo(a) no contexto regular de ensino poderia: estimular um trabalho coletivo na escola regular, contribuir significativamente para a educação 
de crianças surdas, tendo em vista que a sua presença evocaria a representatividade surda na educação; reafirmar a capacidade das pessoas surdas, que via de regra é contestada por uma sociedade conservadora; utilizar técnicas que destacassem as sutilezas linguísticovisuais próprias das pessoas surdas; possibilitar o contato linguístico com crianças surdas, propiciando um processo de aquisição da linguagem para aquelas que ainda não adquiriram sua língua e contribuindo também para a construção de suas identidades surdas (PERLIN, 2007; ROMÁRI0, 2018). Entretanto, isso só seria possível se as condições para a realização de seu trabalho respeitassem as suas diferenças.

É possivel perceber a seguir que as narrativas de Samuel e Samir diferem um pouco das construções de Sofia:

Lá na outra escola eu sou intérprete, porque o professor fala e eu sento ao lado do aluno surdo e faço a interpretação, é diferente, do português para Libras. Eu sou intérprete surdo. Sim, eu aceito. Porque é importante, o surdo precisa do intérprete, então, eu aceito. Precisa dessa adaptação, essa experiência e eu já tenho essa experiência de alguns anos desse contato, então, eu aceito. (Samuel, 27/08/2018).

0 intérprete surdo é necessário, precisa porque ele copia aquilo do professor, faz as adaptações e a interpretação e explica ao surdo, faz tudo detalhado, vai explicando. É difícil. Você precisa pensar, observar bem o professor, ver como você vai fazer essas questões, esperar que o professor finalize para que a gente possa fazer essas adaptações e apresentar. (Samir, 27/08/2018).

Para mim, está certo, porque, no caso, tem um aluno surdo, e aí uma intérprete ouvinte, para mim, não combina. Porque atrapalha um pouco, ela não pode aprender [...] atrapalha um pouco o aluno surdo. Mas um intérprete ouvinte? Aí não combina, o intérprete ouvinte com um aluno surdo na sala de aula, ele pode não entender, não ter atenção. Que é assim, quando vai chamar, aí vai ter "pa pa pa", outro papo, não tem atenção para o surdo. Tem dificuldade de entender palavras e interpretar para ele. Na minha opinião, é melhor o intérprete surdo. Mas, na verdade, intérprete não, mas bom um que é instrutor de Libras, o instrutor é o próprio surdo. No caso, o meu é instrutora de Libras, porque eu acho que é a lei né, que não tem instrutor na prefeitura, aí por isso coloca como intérprete surdo, ai ele troca para $\circ$ ouvinte. Mas ai com o (intérprete) surdo combina, para compartilhar ali com o surdo, porque ele conhece já a Libras, né? Então, ele pode desenvolver a Libras, porque o surdo já sabe Libras, mais que o ouvinte. 0 ouvinte ensina pouco, demora e explica, mas o surdo não, o surdo mostra imagem, mostra as cores e ai o surdo consegue aprender. Eu, na minha opinião, é bom só com o surdo, as pessoas surdas. (Sofia, 22/08/2018) (informações verbais).

Enquanto os dois não criticavam as atividades que desenvolviam, ela, apesar de defender a presença de um(a) profissional surdo(a) na educação das crianças surdas, discordava do termo que era designado a ela e seus(suas) colegas. Segundo a educadora 
surda, a função desempenhada por ela era a de instrutora e não a de intérprete. Existem diferenças relevantes entre uma função e outra. Para entendê-las, é preciso, antes, realizar uma breve incursão sobre a polêmica existente entre os termos instrutor(a) surdo(a) e professor(a) surdo(a). 0 Decreto 5.626/2005 busca elucidar essa questão, afirmando que instrutores(as) são aqueles(as) surdos(as) que exercem função pedagógica em sala de aula junto aos(às) alunos(as) surdos(as), mas possuem apenas formação em nível médio, enquanto professores(as) são aqueles(as) surdos(as) que exercem a mesma função, mas possuem formação em nível superior (BRASIL, 2005, p. 5).

Não obstante as funções de instrutores(as) e professores(as) surjam de forma distinta no Decreto, com base no critério da formação, Romário (2018) questiona essa nomenclatura, baseando-se para tanto nos dados do Instituto Nacional de Estudos e Pesquisas Educacionais Anísio Teixeira (INEP) (2016), que apresenta uma porcentagem de docentes da Educação Básica no Brasil sem Ensino Superior completo de 22,1\% (485.685). Isso mostra que há uma discrepância entre a nomenclatura atribuída às pessoas surdas e não surdas que assumem as mesmas funções pedagógicas, tendo em vista que enquanto pouco mais de um quinto dos(as) docentes ouvintes brasileiros(as) não possuem formação superior e nem por isso são chamados(as) de instrutores(as) ou outras denominações.

Por isso, o presente estudo parte da premissa de que todos(as) os(as) profissionais que atuam no âmbito escolar assumem o papel de educadores(as), sejam ouvintes ou surdos(as), considerando que todas as pessoas envolvidas nos processos educacionais (nesse caso, no espaço escolar) contribuem para a transformação dos indivíduos em sujeitos culturais, explícita ou implicitamente (MEYER et al., 2006).

0 uso do termo "educador(a)" para todos os sujeitos surdos que atuam no âmbito escolar resolve, inclusive, a ausência de consenso existente entre as próprias pessoas surdas em relação ao papel que exerciam. Umas se identificavam como professoras, outras como instrutoras e também como intérpretes. Entretanto, é preciso ressaltar que, embora educativas, as funções são produzidas em tempos e espaços atravessados por relações de poder que posicionam os sujeitos de formas diferentes.

Retomando o esclarecimento sobre a diferença entre instrutorla) e intérprete, a função de intérprete educacional, de acordo com Quadros (2004, p. 63), é a seguinte: "de modo geral, aos intérpretes de Língua de Sinais da área da educação é recomendado redirecionar os questionamentos dos alunos ao professor, pois desta forma o intérprete caracteriza o seu papel na intermediação, mesmo quando este papel é alargado." Apesar de os(as) intérpretes educacionais terem o seu papel alargado, como afirma a autora, isso não pode significar que eles(as) serão inteiramente responsáveis pela educação dos(as) alunos(as) surdos(as). De acordo com a autora, o papel de intérpretes educacionais visa assegurar a participação de alunos(as) surdos(as) durante as aulas, na interação com o(a) docente e colegas. № 
entanto, é preciso que se tenha a compreensão de que, em sala de aula, o(a) professor(a) é, oficialmente, o(a) responsável pela educação das crianças surdas. Diante disso, vê-se que o papel do(a) intérprete embora possa ser amplo - se considerarmos a complexidade da sala de aula na escola regular (dita inclusiva) -, deve ser compartilhado com os(as) docentes ouvintes, tendo cada um(a) clareza de suas responsabilidades.

Não obstante algumas ideias sobre o trabalho pedagógico desenvolvido em sala de aula regular de João Pessoa - PB, na função de intérpretes, se repitam nas narrativas dos sujeitos, julgamos importante cada sujeito expressar a realidade que o envolvia, considerando, sobretudo, que cada experiência é única e cada olhar é singular. Silvana, por exemplo, narrou da seguinte forma:

\begin{abstract}
A professora fica lá, oraliza, explica e o aluno não entende nada e eu também não entendo nada, ai eu ajudo ele na Libras, o meu foco é Libras, certo? Então, a professora está lá escrevendo, escrevendo e ele também não entende nada. Avisos? Como que eu vou avisar? Então, eu preciso entender, aí depois eu vou lá com a professora, ela me informa na questão escrita porque o nível dele é muito baixo, então, ela está lá explicando, explicando e ele não entende. [...] Ele está no quarto ano. Exemplo, [...] eu percebo o tema de Matemática, ai eu chamo lá os números em Libras e vou ensinando a ele e depois eu pergunto se ele entendeu e ele já esqueceu. Outro exemplo, o tema de português, "bola", aí vou e mostro a imagem para ver se ele vai fixando. Ciências, os animais, eu apresento os sinais dos animais, "tartaruga" e ele demora para aprender e eu estou lá junto com ele. (Silvana, 26/11/2018) (informação verbal).
\end{abstract}

A narrativa de Silvana demonstra, principalmente, o seu desconforto com o que vinha ocorrendo no trabalho que havia sido imposto a ela, isto é, a professora ouvinte oralizava, mas tanto o aluno como ela própria não compreendiam o conteúdo. É essa a situação recorrente quando os(as) surdos(as) assumem a função de intérpretes. Eles(as) são confrontados(as) o tempo todo pela óbvia incapacidade de entendimento, tendo em vista o fator biológico. Ao estar em uma sala de aula regular na função de intérprete da língua oral para a língua de sinais, os(as) educadores(as) surdos(as) se veem numa situação que reforça o discurso construído sobre a surdez como materialidade inscrita em um corpo (LOPES, 2007) em detrimento do discurso da diferença linguístico-cultural. Diante dessa situação de invisibilidade da língua de sinais e da valorização da oralização - como uma prática ouvintista (SKLIAR, 2013), ${ }^{6}$ em sala de aula -, como a educadora surda desenvolvia um trabalho de compartilhamento de saberes, de conteúdos escolares com a criança surda se ela não os acessava por falta da compreensão linguística? 
Além disso, Silvana destacou que o foco era o ensino de Libras, dando a entender que ela ensinava Libras com base nos conteúdos trabalhados em sala de aula, por meio de estratégias pedagógicas voltadas para a experiência visual com o uso de imagens. Aparentava haver no mesmo espaço aulas paralelas ou complementares, visto que o conteúdo que ela dizia mediar por meio de interpretação não se relacionava exatamente com o desenvolvido pela professora ouvinte.

Já Samanta ensinava conteúdos de diversas disciplinas por meio da Libras e Libras como conteúdo, mas destaca que eram basicamente adaptações:

\begin{abstract}
Eu faço as adaptaç̃es das atividades, por exemplo, Matemática eu vou e explico em L1, L2 e vou fazendo as adaptações e vou interpretando para ele, vou explicando, as questões de História, Ciências. Meu trabalho é esse aqui, só, ensinar Libras, fazer as adaptações. Eu trabalho igual a professora, pego as atividades dela, combino [...] eu não tenho uma ideia, pego da professora, vou adaptar e passar para o aluno, só isso. Você ensina Libras também? Sim, também. Ciências, questões do corpo humano, sexualidade, vou fazendo as adaptações para o aluno ir desenvolvendo. Enquanto vou trabalhando as atividades, eu também vou trabalhando os sinais, vou explicando a palavra, como escreve a palavra e ele vai sentindo, percebendo essas questões e vai aprendendo. (Samanta, 09/11/2018) (informação verbal).
\end{abstract}

Samanta e Silvana se diferenciam quando Samanta parece assumir uma postura mais autônoma em sala de aula, afirmando que trabalhava igualmente à professora ouvinte, muito embora também tenha dito que se baseava nas atividades da colega, o que transparece certa dependência. Silvana, por sua vez, parecia assumir, naquele contexto, uma posição mais de independência em relação à professora com quem trabalhava. Contudo, tanto Samanta como Silvana pareciam compreender o seu trabalho mais ligado à docência: Samanta por meio de seu discurso e Silvana ao descrever a sua prática.

Enquanto Silvana recorria a estratégias para ter acesso às informações, por exemplo, a escrita, Samir, muitas vezes, precisava pedir que o professor diminuísse o ritmo para que pudesse ensinar ao aluno surdo com o qual trabalhava:

Então, porque, às vezes, tem os ouvintes e os professores surdos, aí o professor ouvinte fica ensinando. Eu digo: "ei, calma, eu preciso pegar isso aí, fazer essa adaptação, estudar, para poder ensinar o surdo", para ter esse contato, que tenha essa troca. Que a gente fica com dúvida, né? 0 aluno surdo fica com dúvida, então precisa dessas adaptações para que eles possam entender, clarear. 0 surdo quando tem essa identidade de troca fica mais fácil para ele entender essa questão da relação entre o ouvinte e o surdo. Sim, eu ensino tudo, todas as disciplinas, eu faço adaptação, escrevo [...]. Libras vem primeiro, depois a escrita, então eu faço as adaptações, ensino, se ele tiver dúvidas ele me pergunta e eu ensino novamente até que 
ele aprenda. Sim, o professor me ajuda. Ele me passa algumas orientações, eu faço as adaptações, crio as estratégias para os surdos, ai há sim essa troca. (Samir, 27/08/2018) (informação verbal).

Samuel, por sua vez, parecia não assumir uma postura crítica em relação ao trabalho pedagógico que desenvolvia. Ele aceitava o processo ao qual era submetido, deixando a língua de sinais em segundo plano, ao ter de oralizar para que pudesse ter o mínimo de diálogo e pudesse ensinar à criança surda por meio das adaptações. Vejamos:

\footnotetext{
[...] o professor ouvinte fica lá na disciplina, exemplo Português, Matemática, ele está lá oralizando, eu espero ele finalizar, vou entendendo o que ele está falando, aí faço as adaptaç̃̃es e explico. Se eu tiver dúvidas, eu chamo, a gente oraliza um pouquinho, ele passa as orientações para mim, eu faço as adaptações, as atividades, os materiais, organizo e passo para o surdo, aí ele aprende. Quando ele está oralizando rápido eu digo: "não, calmal". Peço para que ele tenha um pouco de calma para poder fazer as adaptações para ele entender, aí caso eu não entenda, eu chamo o professor, peço que ele explique, dê exemplos, aí eu faço a adaptação e passo para o surdo. (Samuel, 27/08/2018) (informação verbal).
}

Samir, assim como Samuel, apontou que havia dificuldades no processo de oralização quando o(a) professor(a) falava muito rápido. Eles precisavam pedir o(a) docente diminuir o ritmo, explicasse o conteúdo novamente, a fim de que eles, os intérpretes surdos, o adaptassem para as crianças surdas. Desse modo, Samuel também não expressou uma postura crítica em relação à exposição à língua oral, sem perceberem que a sua língua estava sendo esmaecida diante de um contexto oralista.

As pesquisas sobre a educação de pessoas surdas têm, geralmente, voltado as suas lentes para os(as) alunos(as) surdos(as) no que diz respeito ao processo histórico de desrespeito à língua de sinais (comumente as crianças não têm autonomia para reivindicar seus direitos, apesar de suas identidades e práticas reclamarem por sua língua desde muito cedo) e também às questões das lutas surdas pelo reconhecimento desta língua e da cultura surda. Todavia, a situação apresentada envolve profissionais surdos(as), demonstrando que, mesmo quando esses sujeitos, linguisticamente diferentes, ocupam lugares profissionais que dariam a eles maior autonomia, sua língua e cultura permanecem sendo desrespeitadas.

Essa percepção é apontada por Suelen, demonstrando que o processo de comunicação ficava comprometido, o que inviabilizava o seu trabalho, mesmo ela se declarando oralizada: 
Eu ensino Libras que é a primeira língua. Para mim, a gente começa ensinando Libras e depois português, o L2, que é a segunda língua, aprender a escrever, os dois juntos. Matemática também, ensinar várias matérias também, música em Libras [...]. Ela passa o texto e eu vou explicar para a aluna entender. [... Primeiro eu vejo o que ela está falando, como eu sou oralizada eu vejo o que ela está falando e depois vou passar para ela. Depois eu passo o que a professora está falando para ela entender claro, mas primeiro eu vejo o quadro, vejo os lábios da professora para depois passar para ela. Mas precisa de intérprete junto comigo porque é diferente com o instrutor surdo, eu preciso de um intérprete dentro de sala de aula porque é cansativo ficar vendo os lábios, eu acho que deveria ter um intérprete junto que passa para mim e eu passo para ela. (Suelen, 24/10/2018) (informação verbal).

Esse processo não parecia ser confortável para ela, uma vez que apontou o quão cansativo era sempre ter de fazer leitura labial. Sua fala reivindica indiretamente respeito à sua língua, a língua de sinais. Ademais, revela também que ela não se via como intérprete, ao ponto de propor que fosse inserido(a) um(a) intérprete ouvinte em sua sala de trabalho.

Silvio passava por um processo similar. Ele atuava como intérprete surdo em sala de aula, mas na modalidade da Educação de Jovens e Adultos (EJA), como afirma a seguir:

\begin{abstract}
No planejamento, eu pego um livro, mostro e aí fico mudando as coisas para ver $\circ$ que entendeu, faço um resumo porque alguns textos enormes são difíceis para o surdo e, às vezes, pensam que o surdo já sabe e tal. Já são velhos, uma idade avançada e nunca estudou desde criança e aí eu percebi que eles não conseguiam desenvolver, ai eu pergunto à professora: eu ensino, ensino e ensino mas parece que eles não conseguem aprender, parece que tenho que voltar para alfabetização. (Silvio, 18/09/2018) (informação verbal).
\end{abstract}

Sua fala, porém, demonstrou que a atividade que desenvolvia estava muito mais ligada à docência do que à interpretação, por ele participar do planejamento, fazer as adaptações em relação aos textos que iriam ser trabalhados em sala de aula pela professora ouvinte e, sobretudo, porque afirmou ensinar às pessoas surdas inseridas naquele contexto. Seu trabalho pedagógico parecia assumir uma posição mais de autonomia em vistas de comparação com algum(as) de seus(suas) colegas.

No caso de Sofia, por exemplo, podemos perceber que ela vivenciava uma situação diferente: 
ela saber o que são as palavras e eu vou sinalizando e ela vai mostrar os sinais. É diferente de ouvir, né? 0 ouvinte já fala: "0 que é BO?". Para ela não, ela vai ter que perceber como é. Mas interpretar tudo que ela fala, não, mas ela manda atividade e ela faz todinha, se tem uma palavra que não conhece ela me chama, aí vou ajudar. Minha interação é assim com ela. (Sofia, 22/08/2018) (informação verbal).

Era responsável por uma criança surda da Educação Infantil em fase de alfabetização, momento fundamental no processo de escolarização de qualquer pessoa. 0 fato de o processo de alfabetização da criança surda estar sendo mediado por uma intérprete surda pode representar avanços. Afinal, a mediação em língua de sinais é o diferencial que, muitas vezes, não é observado com outras crianças surdas no contexto da escola regular. Entretanto, na narrativa da educadora surda, duas ações podem ser elencadas: o ensino e a interpretação.

0 primeiro questionamento dá-se no sentido do papel docente na alfabetização das crianças surdas. Nesse momento crucial da vida de uma criança, seja ela surda ou ouvinte, o(a) professor(a) desempenha a função principal. Sem querer entrar nas minúcias dessa situação, é possivel aventar alguns questionamentos a fim de propiciar reflexões secundárias: Quais as implicações dessa situação para a aprendizagem da criança surda? A criança não deveria adquirir primeiramente a lingua de sinais e depois ser alfabetizada em língua portuguesa? Ela já dominava a Libras? E, enfim, qual o papel de fato da professora e da intérprete nesse processo? Mesmo ela sendo considerada intérprete, ela era professora?

Caso a profissional surda desempenhasse uma função de professora, alfabetizando a criança surda, os processos educacionais poderiam surtir efeitos positivos para a criança surda. Mas, como fazê-lo se não possuía plena autonomia para ensinar a criança? Segundo ela, fazia interpretação daquilo que a professora ouvinte ensinava em sala de aula, com base nas escolhas pedagógicas de sua colega ouvinte. No caso da alfabetização da criança surda, com base em um método fônico - como pode ser notado por sua narrativa -, estaria ela exercendo uma pedagogia surda mesmo tendo por base, nessa situação, uma educação pensada por uma professora ouvinte e com metodologias para crianças ouvintes?

Nas palavras de Strobel (2013, p. 92), não, pois "a pedagogia surda é uma educação sonhada pelo povo surdo, visto que a luta atual dos surdos é pela constituição da subjetividade ao jeito surdo de ser." Desse modo, o fato de ser uma pessoa surda desenvolvendo um trabalho pedagógico com base em metodologias ouvintistas, pensadas por e para ouvintes, e sem autonomia, descaracteriza o que a literatura tem compreendido por pedagogia surda, ou seja, uma pedagogia constituída pela subjetividade surda, na qual se valoriza cultural e metodologicamente a experiência visual, a lingua de sinais, as identidades surdas e outros artefatos culturais surdos. Por conseguinte, também acaba descaracterizando o que tem 
sido chamado de trabalho pedagógico surdo, isto é, uma produção surda que envolve não só o trabalho docente, mas também outras atividades profissionais de surdos(as) no âmbito da educação, na qual a sua visão de mundo desconstrua as velhas concepções; construa diferentes discursos pedagógicos com base na cultura surda; desenvolva práticas educacionais condizentes com a experiência visual, com a língua de sinais, com as identidades surdas e com os outros artefatos culturais surdos (SILVA, 2020).

Todavia, parecia haver um descontentamento com essa situação, gerada pela falta de autonomia e, ao mesmo tempo, de ausência de responsabilidade das professoras ouvintes. Tons de criticidade começam a ganhar coro com a narrativa de Sabrina:

A professora ouvinte, exemplo, de Matemática, Português, História, Geografia, Artes... [...] Mas a professora, ela que é a titular da sala, Português, Matemática, as outras disciplinas, ela não faz nada. Nunca tem atividade, fora as disciplinas do AEE, eu digo a ela: "precisa adaptar também"! Mas o foco dela é nos ouvintes, ela não se aproxima. [...] Então, eu percebo as atividades dela e eu mesma vou procurando e adaptando, é muito diferente. Ela não quer ensinar português, ela que é responsável, ela quem tem fluência na disciplina, então, é ela que tem que estar com ele. Por que ela não faz? Porque ela não aceita, ela não quer ele, é complicado. Ela tem Pedagogia, foi trabalhada para isso, ela sabe como lidar [...] 0 foco nele é só Libras. (Sabrina, 26/07/2018) (informação verbal).

Assim como Silvana e Suelen, Sabrina começa a desenhar os aspectos críticos que envolviam a função desempenhada por elas em sala de aula, questionando o trabalho da professora ouvinte. Segundo ela, a professora ouvinte era quem tinha formação pedagógica para trabalhar as questões de Matemática, Língua Portuguesa, História, Geografia, entre outras, o que fazia, mas com foco apenas nos(as) alunos(as) ouvintes, deixando de lado - processo pedagógico da criança surda. Dessa forma, a responsabilidade pelo trabalho pedagógico com os(as) alunos(as) surdos(as) ficava somente para ela. Não obstante tenha afirmado que fazia adaptações a partir do que a professora ouvinte ministrava em sala de aula, a sua ênfase era no ensino da língua de sinais. Os conteúdos de Língua Portuguesa, Matemática, por exemplo, para ela, que tinha formação em Licenciatura em Letras-Libras, pareciam ser difíceis de adaptação, apesar de ela o fazer.

É possível notar nas narrativas surdas que não há uma clareza sobre o papel desempenhado por esses(as) profissionais na escola regular. 0 trabalho de interpretação se confunde com o de ensino, de docência. Podemos considerar que havia, no espaço escolar, uma nova configuração profissional? Se sim, qual seria o papel da professora ouvinte diante desse contexto? 
Vê-se que não há um consenso entre os(as) educadores(a) surdos(as) sobre as atividades que desenvolviam. Cada um(a), ao seu modo, desenvolvia a atividade que achava importante e que conseguia realizar naquele contexto. Samanta, Sabrina, Samuel e Samir, por exemplo, realizavam, praticamente, adaptações na sala de aula regular. Samanta novamente, Silvana, Sabrina e Samir apontaram também que o foco estava sendo o ensino de Libras. 0 ensino de outros conteúdos curriculares também era indicado, porém, muito mais na perspectiva da adaptação e do ensino do que da interpretação, função que thes era atribuída.

Há um emaranhado de questões que envolvem o trabalho pedagógico surdo, que impossibilitam qualquer tipo de classificação ou categorização das atividades que esses sujeitos desenvolviam na escola regular. A problematização de todo esse estado de coisas parece mais interessante, visto que as narrativas apontam diversos caminhos a serem explorados. Como esse trabalho vinha sendo incorporado tem a ver, sobretudo, com aquilo que vinha sendo feito e quais as implicações para a educação das pessoas surdas.

\section{CONSIDERAÇÕES FINAIS}

As análises desenvolvidas nesta pesquisa apontam que, sem desconsiderar a rica possibilidade de surdos(as) atuarem como intérpretes, as condições para a sua atuação em salas de aula regulares, nas situações específicas apontadas por este estudo, eram precárias. Tal precariedade fica patente pela: falta de formação na área de traduçãointerpretação; existência de salários de nível médio não obstante alguns tivessem formação em nível superior; e, principalmente, forma como o processo de tradução e interpretação é realizado (deveria ser realizado da língua vocal-auditiva para a gestual-visual - tradução intermodal).

Ao fazê-lo, as escolas regulares de João Pessoa - PB evidenciam para os(as) profissionais surdos(as) um lugar discursivo e simbólico que, historicamente, a comunidade surda vem tentando desconstruir, isto é, o da surdez como deficiência, tendo em vista que nessa atividade a língua oral se sobrepõe à língua de sinais, forçando-os(as) a retomar históricas práticas oralistas, como a leitura labial e a oralização, mesmo estando em um outro lugar social dentro da escola, o de profissionais. Mesmo assumindo essa outra posição, as relações de poder que constituem o ouvintismo são reinventadas, demarcando outros territórios discursivos para antigas concepções relativas às pessoas surdas.

As narrativas sinalizam que não havia um consenso entre os(as) educadores(as) surdos(a) sobre as atividades que desenvolviam. Cada um(a), ao seu modo, desenvolvia a atividade que achava importante e que conseguia naquele contexto. 0 trabalho pedagógico 
em sala de aula regular transitava entre adaptar atividades, interpretar de uma língua para outra e ensinar.

Pelas condições impostas pela escola regular, parte dos(as) educadores(as) realizavam o seu trabalho pedagógico a partir da prática das educadoras ouvintes em sala de aula regular. Por se basear em metodologias ouvintistas, o trabalho pedagógico surdo em sala de aula acabava sendo descaracterizado, uma vez que, ao forçar uma prática arbitrária, que viola a autonomia e a subjetividade surdas, a escola diminuía a potencialidade pedagógica de educadores(as) surdos(as) que enriqueceria os processos escolares com as suas experiências visuais e linguísticas. Por outro lado, quando prevalecia o ensino de Libras e metodologias visuais, portanto a cultura surda em detrimento do que seria a tradução-interpretação intermodal, os(as) profissionais surdos(as) demonstravam resistência às relações de poder que esse modelo escolar e de trabalho impunha.

Uma das implicações dessa realidade é o fato de profissionais surdos(as) não entrarem em um consenso sobre seu papel: alguns(algumas) se autodeclaravam professores(as), outros(as) instrutores(as) e ainda havia quem se identificasse como intérprete. São produzidas, dessa maneira, identidades profissionais confusas, em decorrência de sua forçosa inserção em relações de trabalho complexas e contraditórias, demostrando, ademais, que não obstante a legislação - Decreto de 5.626/2005 (BRASIL, 2005) - demarque determinados papéis para eles(as) - instrutores(as) e professores(as) - com base em sua formação acadêmica, a prática escolar produzia um papel diferente daquele que prevê a letra da lei: o de intérpretes.

A desvalorização do trabalho pedagógico surdo na escola regular demonstra que a sua inserção nesse espaço pode representar uma conquista para esses(as) profissionais, mas demonstra também que as relações de poder que envolvem o nosso sistema educacional não valorizam as diferenças dos(as) profissionais que não se enquadram nos padrões de normalidade construídos culturalmente.

\section{REFERÊNCIAS}

BRASIL. Decreto $n^{\circ} 5.626$, de 22 de dezembro de 2005. Regulamenta a Lei ${ }^{\circ} 10.436$, de 24 de abril de 2002, que dispõe sobre a Língua Brasileira de Sinais - Libras, e o art. 18 da Lei n’ 10.098, de 19 de dezembro de 2000. Diário Oficial da União, Brasília, DF, 23 dez. 2005.

CAMPELLO, A. R. Intérprete surdo de Língua de Sinais Brasileira: o novo campo de tradução/interpretação cultural e seu desafio. Cadernos de Tradução, v. 11, n. 33, p. 143-167. jan./jun. 2014. 
CARVALHO, D. J. Não basta ser surdo para ser professor: as práticas que constituem o ser professor surdo no espaço da inclusão. 2016. 148 f. Dissertação (Mestrado em Educação) - Centro de Educação, Programa de Pós-Graduação em Educação, Universidade Federal do Espírito Santo, Vitória, 2016.

CUNHA, M. I. Conta-me agora! As narrativas como alternativas pedagógicas na pesquisa e no ensino. Rev. Fac. Educ., v. 23, n. 1-2, p. 185-195, jan./dez. 1997.

DENZIN; N. K.; LINCOLN, Y. S. Introdução: a disciplina e a prática da pesquisa qualitativa. In: DENZIN; N. K.; LINCOLN, Y. S. (org.). 0 planejamento da pesquisa qualitativa: teorias e abordagens. Tradução: Sandra Regina Netz. Porto Alegre: Artmed, 2006. p. 15-41.

DORZIAT, A.; ARAÚJO, J. R.; SOARES, F. P. 0 direito dos surdos à educação: que educação é essa? In: DORZIAT, A. (org.). Estudos surdos: diferentes olhares. 2. ed. Porto Alegre: Mediação, 2017. p. 19-60.

DORZIAT, A. Educação de surdos em tempos de inclusão. Revista Educação Especial, v. 28, n. 52, p. 351-364. maio/ago. 2015.

FERREIRA, J. G. D. Os intérpretes surdos e o processo interpretativo interlíngue intramodal gestual-visual da ASL para Libras. 2019. 135 f. Dissertação (Mestrado em Estudos da Tradução) - Programa de Pós-Graduação em Estudos da Tradução, Centro de Comunicação e Expressão, Universidade Federal de Santa Catarina, Florianópolis, 2019.

INSTITUTO NACIONAL DE ESTUDOS E PESQUISAS EDUCACIONAIS ANISIO. Microdados Censo Escolar 2012. Brasilia, DF: INEP, 2012. Disponivel em: ftp://ftp.inep.gov.br/microdados/micro_censo_escolar_2012.zip. Acesso em: 10 fev. 2019.

JAKOBSON, R. Linguística e comunicação. 24. ed. São Paulo: Cultrix, 2007.

LIMA, N. M. F. A inclusão escolar de surdos: o dito e o feito. In: LODI, A. C. B.; MÉLO, A. D. B.; FERNANDES, E. (org.). Letramento, bilinguismo e educação de surdos. Porto Alegre: Mediação, 2012. p. 303-332.

LOPES, M. C.; MENEZES, E. P. C. Inclusão de alunos surdos na escola regular. Cadernos de Educação, n. 36, p. 69-90, maio/ago. 2010.

LOPES, M. C. Surdez \& Educação. Belo Horizonte: Autêntica, 2007.

MARTINS, V. R. 0; NASCIMENTO, L. C. R. Educação de surdos e as resistências na atualidade: diálogos necessários sobre a educação e a função de intérpretes educacionais. Revista Espaço, n. 46, p. 97-117, jul./dez. 2016.

MEYER, D. E. E. et al. "Você aprende. A gente ensina?" Interrogando relações entre educação e saúde desde a perspectiva da vulnerabilidade. Cad. Saúde Pública, v. 22, n. 6, p. 1335-1342, 2006.

MUNDAY, J. Key concepts. In: MUNDAY, J. (org.). The Routledge Companion to Translation Studies. NewYork: Routledge, 2009. p. 166-240. 
PERLIN, G. Inclusão escolar: desafios. [S. l.: s. n.], 2007. Disponível em:

http://proex.pucminas.br/sociedadeinclusiva/anaispdf/gladis.pdf. Acessado em: 20 jan. 2020.

QUADROS, R. M. 0 tradutor e intérprete de língua brasileira de sinais e língua portuguesa. Brasília: MEC; SEESP, 2004.

RODRIGUES, C. H. Formação de intérpretes e tradutores de língua de sinais nas universidades federais brasileiras: constatações, desafios e propostas para o desenho curricular. Translatio, v. 15, p. 197-222, 2018.

ROMÁRIO, L. Pedagogia surda: cultura, diferença e construção de identidades. Curitiba: CRV, 2018.

SEGALA, R. Tradução intermodal e intersemiótica/interlinguística: português escrito para a língua de sinais. Dissertação (Mestrado em Estudos da Tradução) - Programa de Pós-Graduação em Estudos da Tradução, Centro de Comunicação e Expressão, Universidade Federal de Santa Catarina, Florianópolis, 2010.

SILVA, L. R. 0 trabalho pedagógico surdo na escola regular. 2020. 240 f. Tese (Doutorado em Educação) - Programa de Pós-Graduação em Educação, Centro de Educação, Universidade Federal da Paraíba, João Pessoa, 2020.

SILVEIRA, R. M. H. A entrevista na pesquisa em educação - uma arena de significados. In: COSTA, M. V. Caminhos investigativos II: outros modos de pensar e fazer pesquisa em educação. 2. ed. Rio de Janeiro: Lamparina Editora, 2007. p. 117-138.

SKLIAR, C. Os estudos surdos em educação: problematizando a normalidade. In: SKLIAR, C. (org.). A surdez: um olhar sobre as diferenças. 6. ed. Porto Alegre: Mediação, 2013. p. 7-32.

SOUZA, R. M. 0 professor intérprete de lingua de sinais em sala de aula: ponto de partida para se repensar a relação ensino, sujeito e linguagem. Educação Temática Digital, p. 154-170, 2007.

STROBEL, K. As imagens do outro sobre a cultura surda. 3. ed. rev. Florianópolis: Editora da UFSC, 2013.

Endereço para correspondência: Avenida Ten. Raimundo Rocha, 1639, IISCA/UFCA, Bloco C, Sala 04, Cidade Universitária, 63048-080, Juazeiro do Norte, Ceará, Brasil; lucas.romario@ufca.edu.br 
